\title{
Bridging the Gap Between Wikipedia and Academia
}

\author{
Dariusz Jemielniak \\ New Research on Digital Societies (NeRDS) group, Kozminski University, Jagiellonska 59, 03-301 Warszawa, \\ Poland. E-mail: darekj@kozminski.edu.pl
}

Eduard Aibar

Research Group on Open Science \& Innovation, Universitat Oberta de Catalunya, Av. Tibidabo, 39-43, 08035

Barcelona, Spain. E-mail: eaibar@uoc.edu

In this opinion piece, we would like to present a short literature review of perceptions and reservations towards Wikipedia in academia, address the common questions about overall reliability of Wikipedia entries, review the actual practices of Wikipedia usage in academia, and conclude with possible scenarios for a peaceful coexistence. Because Wikipedia is a regular topic of JASIST publications (Lim, 2009; Meseguer-Artola, Aibar, Lladós, Minguillón, \& Lerga, 2015; Mesgari, Okoli, Mehdi, Nielsen, \& Lanamäki, 2015; Okoli, Mehdi, Mesgari, Nielsen, \& Lanamäki, 2014), we hope to start a useful discussion with the right audience.

\section{Common View of Academics on Wikipedia}

Michael Gorman, former president of the American Library Association, once stated that "a professor who encourages the use of Wikipedia is the intellectual equivalent of a dietician who recommends a steady diet of Big Macs with everything" (as cited in, Reagle, 2010, p. 138). This quote quite accurately exemplifies the general mistrust many academics share towards Wikipedia. Those who contribute to Wikipedia are perceived as having "hive mind mentality" and subscribing to "digital Maoism," which deprecates intelligence and destroys individualism (Lanier, 2006). Editing Wikipedia is perceived as something unworthy; that "only schmucks would do that. Or losers" (Andrew Keen as cited in, Parvaz, 2011). In general, Wikipedians are considered at best to be a group of amateurs unable to deliver at high academic standards (Keen, 2007). Some scholars even insist that Wikipedia cannot possibly survive, because of its radically open model, encouraging vandal- isms, and a community whose enthusiasm will inevitably wane: Since 2005 Eric Goldman, a professor of law at Santa Clara University, keeps predicting that "Wikipedia Will Fail Within 5 Years" (Goldman, 2005), changing only the expected demise date (Anderson, 2009).

Even people sympathetic to open collaboration models, consider Wikipedia to rely mainly on the wisdom of crowds, not necessarily on actual expertise (Surowiecki, 2004). It is called a "flawed knowledge community" (Roberts \& Peters, 2011 , p. 36), a broken surrogate. And the common view seems to be that even if experts participate, they may experience a hard time on Wikipedia. This is so:

Since experts enjoy no special privileges in dispute resolution, and since there are many aggressive non-experts who care deeply about a wide variety of topics, Wikipedia's anti-expert tendencies unsurprisingly work against continual improvement (Sanger, 2009, p. 64).

Moreover, for some academics Wikipedia is synonymous with plagiarism. Even though Wikipedia itself could serve as a paragon of proper copyright policies, the fact that so many students use Wikipedia (Lim, 2009), and also sometimes copy from Wikipedia verbatim, may result in Wikipedia being guilty by association.

A lot of the general distrust towards Wikipedia stems from the view that a collaboratively generated encyclopedia cannot meet the high standards of quality (Denning, Horning, Parnas, \& Weinstein, 2005; Wallace \& Van Fleet, 2005). Nevertheless, it is worth noting that the specific details of Wikipedia's collaborative editing system are often not very well known, and sometimes misunderstood, even by academics (Aibar, Lladós-Masllorens, Meseguer-Artola, Minguillón, \& Lerga, 2015) Regarding the editors' profiles, a recent survey concluded that most of them are well educated and $61 \%$ have, at least, a college degree (Wikimedia Foundation, 2011). 
Although many of the reservations are understandable, there is also an obvious elephant in the room: Wikipedia challenges the established model of distribution of knowledge and the traditional authority of academia (Eijkman, 2010; O'Neil, 2010). The Internet as a medium generally redefines the role of authority and expertise (Battles, 2007), as well as collaborative work practices (Ciesielska \& Petersen, 2013), but Wikipedia, in particular, directly questions the dominant knowledge elites and their monopoly on knowledge dissemination (Hartelius, 2010). As Clay Shirky observes:

In fact what Wikipedia presages is a change in the nature of authority. Prior to Britannica, most encyclopaedias derived their authority from the author. Britannica came along and made the relatively radical assertion that you could vest authority in an institution. You trust Britannica, and then we in turn go out and get the people to write the articles. What Wikipedia suggests is that you can vest authority in a visible process. As long as you can see how Wikipedia's working, and can see that the results are acceptable, you can come over time to trust that. And that is a really profound challenge to our notions of what it means to be an institution, what it means to trust something, what it means to have authority in this society (quoted in: Gauntlett, 2009, p. 42).

Fundamentally, the most important reservation with regard to Wikipedia is that it is basically not reliable enough. However, this perception of Wikipedia's quality may be biased (Flanagin \& Metzger, 2011), and therefore it is worth having a look at more systematic studies of Wikipedia's reliability.

\section{Reliability of Wikipedia Entries}

Since the very early days of Wikipedia, its content has been actually found quite credible (Chesney, 2006). As early as in 2005 it was described as going "head to head" with Encyclopedia Britannica in terms of the number of errors in a study published by Nature (Giles, 2005). Quite obviously, it is also much better referenced (Rivington, 2007).

It is worth noting that with over 4 million entries, any reliability studies have to be based on evaluating a tiny fraction of Wikipedia, typically in a chosen specialized topic. For instance, information about mental health on Wikipedia seems to be of high quality (as compared to Encyclopedia Britannica, psychiatry textbooks, and other websites), although not very readable (Reavley et al., 2012). In general, some scholars show that Wikipedia has high overall linguistic readability (Yasseri \& Kertész, 2012), whereas according others it is not so good (Lucassen, Dijkstra, \& Schraagen, 2012).

The study of references provides another important axis for the evaluation of reliability, because, following one of its central content policies, many Wikipedia entries list citations and references to previous publications. Recent studies show that there has been an increasing trend in Wikipedia to include references to standard scientific journals, and that the citation frequency of those journals is very similar to the patterns in the scientific literature (Nielsen, 2007). It has also been found that a journal's academic status (understood as its impact factor) is the most important predictor of its appearance in Wikipedia references (Teplitskiy, Lu, \& Duede, 2015).

There is also some evidence that Wikipedia coverage of scientific topics with potential social effects like global warming or climate change tend to reflect the hegemonic scientific consensus (its anthropogenic origin) rather than denialist positions (Esteves \& Cukierman, 2012). Our own ongoing research on socially controversial scientific topics in the Spanish ${ }^{1}$ and Polish Wikipedia supports that view.

\section{Actual Usage of Wikipedia by Scholars}

It is worth observing that the perception of Wikipedia's quality has improved over time, particularly among academics (Shachaf, 2009; Soules, 2015). There already are scholars who openly and clearly support it (Bateman \& Logan, 2010; Heilman et al., 2011), and there already are institutional initiatives encouraging professors to contribute to Wikipedia. The Public Policy Initiative, for instance, was a pilot project launched by the Wikimedia Foundation in 2010-11 in order to involve professors at public policy programs in US universities, in the design of assignments to make students improve related articles in the English Wikimedia. This project inspired the creation of the Wikipedia Education Program that has in recent years established different partnerships with universities, scientific societies, and cultural institutions across the world, with similar aims. Notably, in 2011 President Erik Olin Wright of the American Sociological Association called for improvement of sociological articles on Wikipedia, ${ }^{2}$ and a similar call was issued by the American Psychological Association ${ }^{3}$; the Association for Psychological Science mobilized more than 3,300 scholars and students to edit Wikipedia's psychological topics, ${ }^{4}$ etc. More and more academics also introduce Wikipedia editing as a regular teaching tool (Konieczny, 2012). They also reach out and successfully conduct research projects, including experimental ones (see e.g, Algan, Benkler, Morell, \& Hergueux, 2013).

In a recent study based on a large survey given to all teaching staff at two Spanish universities (with 913 valid responses on a questionnaire with 50 questions), Aibar et al. (2015) show that the overall quality of Wikipedia articles is rather positively valued by most faculty members of two large Spanish universities. Most of them declare to be frequent users of Wikipedia, particularly for personal and professional matters not in their field of expertise. Though few of them use Wikipedia for teaching purposes, those in STEM fields do it more than their colleagues in social sciences and humanities. Nevertheless, private instances of use are not matched by public uses (i.e., those that require some

\footnotetext{
${ }^{1}$ Compare: http://osi.blogs.uoc.edu/projects/

${ }^{2} \mathrm{http} / / / \mathrm{www}$.asanet.org/footnotes/nov11/wikipedia_1111.html

${ }^{3}$ http://www.apa.org/science/about/psa/2010/12/wikipedia-change.aspx

${ }^{4}$ https://www.psychologicalscience.org/index.php/members/aps-wikipediainitiative
} 
sort of publicly stated commitment, like recommending it to other people). Most faculty think Wikipedia is not well regarded by their colleagues as a respectable source of information. But because colleagues act as a strong role model in academic life, a negative feedback loop is created: because peers do not talk much about it, most faculty members tend to think their colleagues do not use it because they find it inappropriate or unreliable. This process prevents them from publicly exposing their own positive view, in spite of being regular users. A basic tension between scientific culture and peer production could be hypothesized as an explanation of this phenomenon, though it is eventually modulated by the particular subcultures of more specific scientific disciplines.

\section{Possible Directions for Peaceful Coexistence}

Wikipedia can stimulate egalitarian knowledge sharing (Cammaerts, 2008; Hansen, Berente, \& Lyytinen, 2009; Jemielniak, 2015). But there are many other good reasons to introduce Wikipedia into academia. First of all, Wikipedia has the readership most of us can only dream of. Contributing to Wikipedia helps in popularizing our fields and research, all to the benefit of the wider society.

In fact, it can be said that Wikipedia has become the main platform for the public communication of science. Recent studies on communication and public perception of science agree that the Internet has become, for most people, the main source of scientific information (Brossard \& Scheufele, 2013). In recent years the Internet has surpassed traditional media in this regard: newspapers, radio, and television. According to a study by the National Science Foundation (USA) more than $60 \%$ of citizens seeking scientific information on specific topics, turn first to the Internet whereas only $12 \%$ are still using the online versions of traditional media-newspapers or magazines (National Science Board, 2012). Data from the Spanish Survey on the Social Perception of Science (FECYT, 2012) show that the Internet is also the main source of scientific information for the Spanish public. When asked about the type of Internet resources used for scientific information, $21.7 \%$ say they use Wikipedia as their main source. Only blogs and social media rated higher in terms of use, but since both include a large variety of instances, Wikipedia can actually be considered the most consulted singular source and, therefore, the most important channel for the public communication of science nowadays.

Moreover, there are also good practical reasons to use Wikipedia in the classroom. Assigning encyclopedia article development as a graded task not only makes the professor's life easier (a lot of evaluation will be done by the community, plagiarism will be spotted, etc.), but also is a truly academic exercise. After all, writing a Wikipedia article requires reviewing academic sources, synthesizing knowledge, using proper references, and writing clearly. When one also takes into account that students are more motivated to write an article for a wide public, rather than an essay that will go to the shredder after grading, it is difficult to under- stand why still so few of us choose this path. Finally, there is also an ethical argument to be made: because the professors and students are in the top $1 \%$ of the privileged in terms of access to knowledge and education, it seems to be a good deed to help those who are less fortunate by developing free knowledge reservoirs, especially if it is done at zero cost.

For the good or for the bad, Wikipedia will stay and will most likely serve as the main source of knowledge-including scientific knowledge-for the generations to come. If we do not start contributing to Wikipedia, as well as using it in classrooms, this train is going to leave without us. It is good for students, it is good for the society, and it is good for usboth because it helps our ideas reach a wider audience, and because it saves us time in class assignments. Thus, we would like to end this piece with a strong appeal to fellow professors to start openly and actively collaborating with Wikipedia.

\section{Acknowledgment}

Writing this article on Dariusz Jemielniak's part was possible thanks to a part of a research grant from the Polish National Science Center (no. UMO-2012/05/E/HS4/01498) and on Eduard Aibar's part thanks to the FECYT research grant FCT-14-8269.

\section{References}

Aibar, E., Lladós-Masllorens, J., Meseguer-Artola, A., Minguillón, J., \& Lerga, M. (2015). Wikipedia at university: What faculty think and do about it. The Electronic Library, 33(4), 668-683.

Algan, Y., Benkler, Y., Morell, M.F., \& Hergueux, J. (2013). Cooperation in a Peer Production Economy Experimental Evidence from Wikipedia. Paper presented at the Workshop on Information Systems and Economics, Milan, Italy.

Anderson, N. (2009). Doomed: Why Wikipedia will fail. Ars Technica. Retrieved from http://arstechnica.com/business/2009/2002/doomedwhy-wikipedia-will-fail/.

Bateman, A., \& Logan, D.W. (2010). Time to underpin Wikipedia wisdom. Nature, 468(7325), 765-765.

Battles, M. (2007). Authority of a new kind. Encyclopedia Britannica Blog. Retrieved from http://www.britannica.com/blogs/2007/2006/ authority-of-a-new-kind/.

Brossard, D., \& Scheufele, D.A. (2013). Science, new media, and the public. Science, 339(6115), 40-41.

Cammaerts, B. (2008). Critiques on the participatory potentials of Web 2.0. Communication, Culture \& Critique, 1(4), 358-377.

Chesney, T. (2006). An empirical examination of Wikipedia's credibility. First Monday, 11(11). Retrieved from http://firstmonday.org/htbin/ cgiwrap/bin/ojs/index.php/fm/article/view/1413/1331.

Ciesielska, M., \& Petersen, G. (2013). Boundary object as a trust buffer. The study of an open source code repository. Tamara Journal for Critical Organization Inquiry, 11(3), 5-14.

Denning, P., Horning, J., Parnas, D., \& Weinstein, L. (2005). Wikipedia risks. Communications of the ACM, 48(12), 152-152.

Eijkman, H. (2010). Academics and Wikipedia: Reframing Web 2.0+ as a disruptor of traditional academic power-knowledge arrangements. Campus-Wide Information Systems, 27(3), 173-185.

Esteves, B., \& Cukierman, H. (2012). The climate change controversy through 15 articles of Portuguese Wikipedia. Retrieved from https:// wikipedia-academy.de/w/images.wikipedia-academy-2012/c/c6/5_Paper_ Bernardo_Esteves_Henrique_Cukierman.pdf 
FECYT (2012). Encuesta de Percepción Social de la Ciencia. Retrieved from http://icono.fecyt.es/informesypublicaciones/Documents/Percepción_ Social_2012.pdf

Flanagin, A.J., \& Metzger, M.J. (2011). From Encyclopædia Britannica to Wikipedia. Information, Communication \& Society, 14(3), 355-374.

Gauntlett, D. (2009). Case study: Wikipedia. In G. Creeber \& R. Martin (Eds.), Digital cultures. Berkshire - New York: Open University Press.

Giles, J. (2005). Internet encyclopaedias go head to head. Nature, 438, 900-901.

Goldman, E. (2005). Wikipedia will fail within 5 years. Technology \& Marketing Law Blog. Retrieved from http://blog.ericgoldman.org/ archives/2005/2012/wikipedia_will.htm.

Hansen, S., Berente, N., \& Lyytinen, K. (2009). Wikipedia, critical social theory, and the possibility of rational discourse. The Information Society, 25(1), 38-59.

Hartelius, E.J. (2010). Wikipedia and the emergence of dialogic expertise. Southern Communication Journal, 75(5), 505-526.

Heilman, J.M., Kemmann, E., Bonert, M., Chatterjee, A., Ragar, B., Beards, G.M., ..., Laurent, M.R. (2011). Wikipedia: A key tool for global public health promotion. Journal of Medical Internet Research, 13(1), e14. Retrieved from http://www.ncbi.nlm.nih.gov/pmc/articles/PMC3221335/.

Jemielniak, D. (2015). Naturally emerging regulation and the danger of delegitimizing conventional leadership: Drawing on the example of Wikipedia. In H. Bradbury (Ed.), The SAGE handbook of action research. London - New Delphi - Thousand Oaks: Sage.

Keen, A. (2007). The cult of the amateur: How today's internet is killing our culture. New York: Broadway Business.

Konieczny, P. (2012). Wikis and Wikipedia as a teaching tool: Five years later. First Monday, 17(9). Retrieved from http://firstmonday. org/htbin/cgiwrap/bin/ojs/index.php/fm/article/viewArticle/3583/3313.

Lanier, J. (2006). Digital maoism. The hazards of the new online collectivism. The Edge.org. Retrieved from http://edge.org/conversation/digital-maoism-the-hazards-of-the-new-online-collectivism.

Lim, S. (2009). How and why do college students use Wikipedia? Journal of the American Society for Information Science and Technology, 60(11), 2189-2202.

Lucassen, T., Dijkstra, R., \& Schraagen, J.M. (2012). Readability of Wikipedia. First Monday, 17(9). Retrieved from http://www.uic.edu/ htbin/cgiwrap/bin/ojs/index.php/fm/article/view/3916/3297.

Meseguer-Artola, A., Aibar, E., Lladós, J., Minguillón, J., \& Lerga, M. (2015). Factors that influence the teaching use of Wikipedia in higher education. Journal of the Association for Information Science and Technology, DOI: 10.1002/asi.23488.

Mesgari, M., Okoli, C., Mehdi, M., Nielsen, F.Å., \& Lanamäki, A. (2015). "The sum of all human knowledge": A systematic review of scholarly research on the content of Wikipedia. Journal of the Association for Information Science and Technology, 66(2), 219-245.
National Science Board (2012). Science and engineering indicators 2012. Washington, DC: National Science Foundation.

Nielsen, F. A. (2007). Scientific citations in Wikipedia. First Monday, (12) 8, http://firstmonday.org/issues/issue12_8/nielsen/index.html.

Okoli, C., Mehdi, M., Mesgari, M., Nielsen, F.Å., \& Lanamäki, A. (2014). Wikipedia in the eyes of its beholders: A systematic review of scholarly research on Wikipedia readers and readership. Journal of the Association for Information Science and Technology, 65(12), 2381-2403.

O'Neil, M. (2010). Wikipedia and authority. In G. Lovink \& N. Tkacz (Eds.), Critical point of view: A Wikipedia reader. Amsterdam: Institute of Network Cultures.

Parvaz, D. (2011). Look it up: Wikipedia turns 10 AlJazeera.com. Retrieved from http://www.aljazeera.com/indepth/features/2011/2001/ 201111571716655385.html

Reagle, J.M. (2010). Good faith collaboration: The culture of Wikipedia. Cambridge, MA: MIT Press.

Reavley, N., Mackinnon, A., Morgan, A., Alvarez-Jimenez, M., Hetrick, S., Killackey, E.,..., Jorm, J.F. (2012). Quality of information sources about mental disorders: A comparison of Wikipedia with centrally controlled web and printed sources. Psychological Medicine, 48(8), 1753-1762.

Rivington, J. (2007). Wikipedia guns for Britannica extermination. TechRadar. Retrieved from http://www.techradar.com/news/internet/ broadband/wikipedia-guns-for-britannica-extermination-132792.

Roberts, P., \& Peters, M.A. (2011). From Castalia to Wikipedia: Openness and closure in knowledge communities. E-Learning and Digital Media, 8(1), 36-46.

Sanger, L.M. (2009). The fate of expertise after Wikipedia. Episteme, $6(01), 52-73$.

Shachaf, P. (2009). The paradox of expertise: Is the Wikipedia reference desk as good as your library? Journal of Documentation, 65(6), 977-996.

Soules, A. (2015). Faculty perception of Wikipedia in the California State University System. New Library World, 116(3/4), 213-226.

Surowiecki, J. (2004). The wisdom of crowds. New York: Anchor Books.

Teplitskiy, M., Lu, G., \& Duede, E. (2015). Amplifying the impact of open access: Wikipedia and the diffusion of science. arXiv. Retrieved from http://arxiv.org/abs/1506.07608.

Wallace, D.P., \& Van Fleet, C. (2005). The democratization of information? Wikipedia as a reference resource. Reference \& User Services Quarterly, 45(2), 100-103.

Wikimedia Foundation (2011). Editor Survey Report. Retrieved from http://upload.wikimedia.org/wikipedia/commons/7/76/Editor_Survey_ Report_-_April_2011.pdf. San Francisco: Wikimedia Foundation.

Yasseri, T., \& Kertész, J. (2012). Value production in a collaborative environment. arXiv, preprint arXiv:1208.5130. Retrieved from http:// arxiv.org/pdf/1208.5130v2011.pdf. 